\title{
Diet and dental morphology of two coexisting Aethomys species (Rodentia) in Mozambique. Implications for diet reconstruction in related extinct species from South Africa
}

\author{
Christiane DENYS
}

\begin{abstract}
Denys C. 1994. Diet and dental morphology of two coexisting Aethomys species (Rodentia) in Mozambique. Implications for diet reconstruction in related extinct species from South Africa. Acta theriol. 39: 357-364.
\end{abstract}

The examination of dental morphology of coexisting modern Aethomys namaquensis Smith, 1834 and A. chrysophilus de Winton, 1896 from Mozambique, whose diet has been studied in the field, shows that the development of stephanodont crests and the multiplication of supplementary cusps on labial side of the lower molars is associated with a mainly vegetarian diet. To the most specialized dentition corresponds the most specialized diet. The application of these results to two coexisting Aethomys species from the fossil site of Langebaanweg (Pliocene, South Africa) allows to conclude that their dental differences correspond to different paleodiets. Moerover, the A. namaquensis lineage shows during Plio- Pleistocene times a shift in dental morphology corresponding to an evolution toward a more vegetarian diet. The comparative tooth anatomy seems to be a reliable method for determining diet of extinct rodents species, their close or less close relatives, when diets of extant species are precisely known.

URA 327 CNRS (Montpellier) and Lab. Mammiferes et Oiseaux, M.N.H.N., 55, Rue Buffon, 75005 Paris, France

Key words: Aethomys, Muridae, paleodiets, Plio-Pleistocene, Africa, odontology

\section{Introduction}

Mammalian paleontologists have in many cases only the remains of teeth at their disposal. This is usually sufficient to determine their systematic position. Another aim of palaeontologists is to interpret paleodiets from dental morphology in order to reconstruct the way of life of past mammals, and also to find the significance of some evolutionary trends. For this purpose, comparative anatomy is one of the methods available. Although, it has been demonstrated, for some large mammals, that tooth morphology does reflect diet (Kay and Hylander 1978), this assertion has not yet been verified for many small mammals, and among them rodents. However, in an actualistic approach, van der Meulen and de Bruijn (1982) have attempted to extrapolate from dental morphology and ecology of the living, the diet and biotope of extinct Miocene Gliridae species. Such works are very rare, especially for tropical rodents whose habits and diet are poorly known, while the knowledge of the rodent fossil record is increasing in addition to its use in palaeo- 
ecological interpretations of fossil sites. This has lead to the description of numerous evolutionary dental trends, some being well known (Stehlin and Schaub 1951, Misonne 1969, Michaux 1971, Jaeger 1983). In most of these, hypothesis concerning the progressive acquisition of a more specialized diet has been proposed but not tested due to the extinct status of the concerned genera or species.

It is generally admitted that today the climatic conditions of tropical Africa approach those which prevailed in Europe during Cenozoic time. Therefore, the precise knowledge of diet and related dental patterns exhibited by some modern rodents of Africa would be of interest for the interpretation of some dental patterns exhibited by extinct rodents. Further, this could contribute to test hypotheses concerning evolutionary tendencies both in African and European rodents lineages during Neogene.

In Africa, very few field studies have been devoted to the diet of rodents. Gliwicz $(1985,1987)$ has conducted ecological study of a rodent community of an African dry savanna of Mozambique. This ecological study gave an interesting example of niche segregation between two species of the genus Aethomys: A. namaquensis Smith, 1834 and A. chrysophilus de Winton, 1896. Evidence was proposed for differences in habitat and diet, emphasized during the dry season. More than 50 skulls of these Aethomys were prepared. The careful examination of this material provides the opportunity to compare the diet and dental morphology in this genus. Moreover, many fossil species of Aethomys have been found in Plio-Pleistocene sites of East and South Africa (Denys 1990a, b). Two cohabiting fossil species of Aethomys have been described from the Langebaanweg site in South Africa by Denys (1990a). Their morphology places them very close to modern Aethomys species studied by Gliwicz $(1985,1987)$. Consequently, the aim of this paper is first to characterize the dental morphological features of the modern species of Aethomys related to their diet and second to apply the results to the fossil species of the Langebaanweg site. The latter results could provide further insights on the evolution of the genus in South Africa during Plio-Pleistocene times. The characterization of dental pattern related to diet in Aethomys could bring new elements to the interpretation of some of the extinct Miocene muroid genera of Europe and Africa.

\section{Systematics and phylogeny of the genus Aethomys}

Aethomys, the bush rats are Murinae species spread all over tropical Africa in the savannah regions. Generally, they have the external aspect and size of Rattus rattus. According to the last revision of the genus (Davis 1975), there are at least 9 recognized species of Aethomys Thomas, 1915. The two species studied by Gliwicz $(1985,1987)$ and found in Mozambique both belong to the Zambezian savannah domain and have been characterized by Davis (1975). They are: A. chrysophilus and A. namaquensis. Davis (1975) has created a sub-genus Micaelamys to include species showing an accessory anterior cusp on the lower $\mathrm{M}_{1}$ (e.g. A. namaquensis).

Denys (1990a, b) described the Langebaanweg Pliocene species and researched the phylogenetic relationships between fossil Aethomys species and modern ones. 
A. modernis Denys, 1990 of Langebaanweg has relatively modern characters, and could have been the ancestor of A. chrysophilus. A. adamanticola Denys, 1990 from Langebaanweg retained more primitive characters, some of them being found both in $A$. namaquensis and $A$. hindei, a species from East Africa.

\section{Diets in Aethomys}

Previous studies on diet of Aethomys spp. were lacking in precision. In South Africa, A. namaquensis would be vegetarian (Shortridge 1934), omnivorous (Roberts 1951) or granivorous (Smithers 1971). In South Africa, Smithers (1971, 1983) reports $A$. chrysophilus as a seedeater, feeding on grass and seeds, but gnawing also on nuts, fruits. Shortridge (1934) states they subsist on grain but are omnivorous. According to Jacobsen (1977) they also feed on seeds of Hibiscus engleri. In central Transvaal, they feed on seeds of Diodea natalensis and Pavonia transvaalensis (Jacobsen 1977). In East Africa, Vesey-Fitzgerald (1966) reported A. chrysophilus feeding on the fallen fruits of Combretum and Grevia. More generally, for Kingdon (1974), Aethomys belongs to the ancestral group of omnivorous african murine ("Rattus division" of Misonne 1969) and among this group, A. namaquensis would be the species linking the ancestral group with a special african radiation of herbivorous murids (Misonne 1969).

Gliwicz $(1985,1987)$ has shown that in Mozambique, A. namaquensis was found in rocky slopes of the hills while A. chrysophilus was more widely associated with grassy lower zones. During the dry season, the $\operatorname{diet}$ of $A$. namaquensis was mostly composed of green parts of plants (no insects at all have been found) while $A$. chrysophilus, to the contrary, fed on starchy vegetarian food and insects. On average, during all the year A. namaquensis was more specialized in plants while A. chrysophilus ate in equal parts insects, starchy food, (deshy fruits, starch of seeds and bulbs), green plants (leaves and stems).

\section{Material and methods}

The dental morphology of the specimens attributed to A. namaquensis and A. chrysophilus that had been collected by Gliwicz in Mozambique has been studied. Their diet was studied in the field by analyses of the stomach contents under microscope of high magnification (Gliwicz 1985, 1987). Skulls of individuals collected and studied by Gliwicz are now housed at the Institute of Systematics and Evolution of Animals in Kraków (Poland). Comparisons have been made successively with modern Aethomys material from the Transvaal Museum, the Los Angeles County Museum, the Natural History Museum of London, the Natural History Museum of Paris and with fossils from the South African Museum (Cape Town, South Africa). The dental nomenclature is adapted here from Denys et al. 1992.

\section{Results}

\section{A. namaquensis and A. chrysophilus from Mozambique}

Young individuals (stages of molar wear 1 to 3 ), show a difference in size and surface of the molars between A. namaquensis and A. chrysophilus (Fig. 1). A. na- 

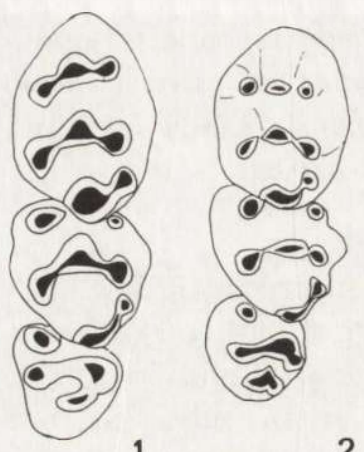

2
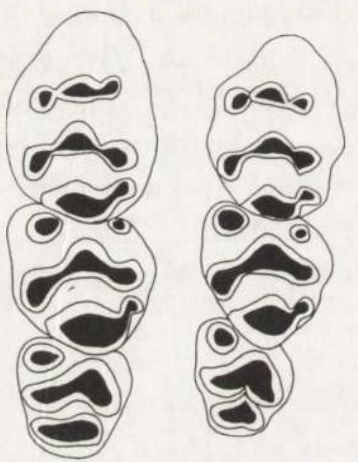

5

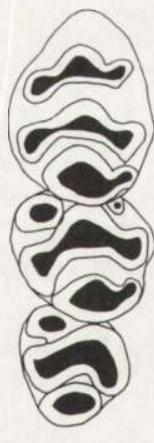

9

6
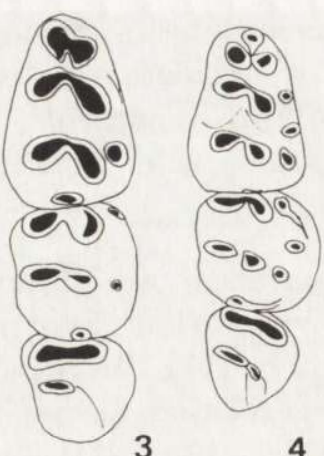

4
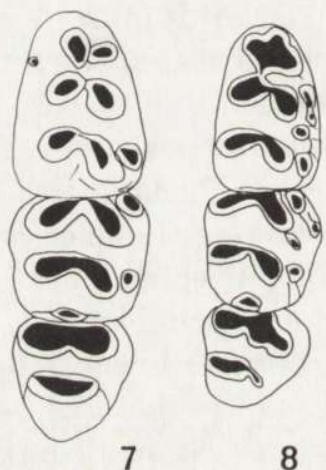

8
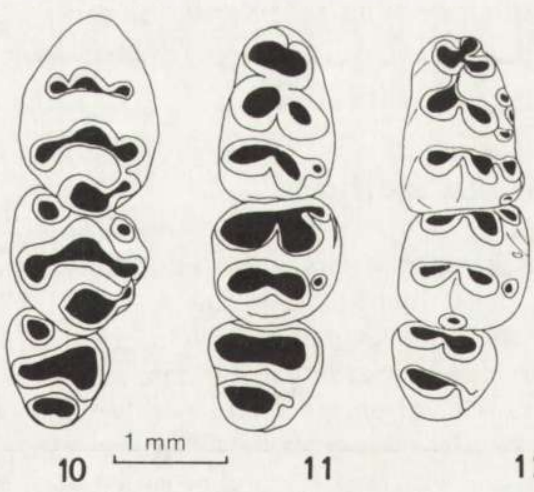

Fig. 1. Dental patterns of Aethomys chrysophilus and $A$. namaquensis. Specimens collected by Gliwicz $(1985,1987)$ housed at Inst. Syst. Evol. Kraków (Poland). Top raw: molar raws of $A$. chrysophilus $(1,3$, $\mathrm{M} / 10177 / 90)$ and $A$. namaquensis $(2,4$, $\mathrm{M} / 10173 / 90$ ) from Mozambique at wear stage 1 (the upper $\mathrm{M}^{3}$ are germs). Middle raw: Wear stages $2-3, A$. chrysophilus (5, $7, \mathrm{M} / 10151 / 90)$ and $A$. namaquensis $(6,8$, $\mathrm{M} / 10181 / 90$ ). Bottom raw: wear stages $4-5$ A. chrysophilus $(9,11, \mathrm{M} / 10151 / 90)$ and $A$.

12 namaquensis $(10,12, \mathrm{M} / 10181 / 90)$.

maquensis has smaller molars than A. chrysophilus, but in stages of wear 4-5 the size difference decreases.

Another difference between both species is the disposition of the cusps. They are higher, more bented towards the back of the teeth, and more fused in A. chrysophilus than in A. namaquensis, in where they are better individualized. The cusps of the first lobe of the $\mathrm{M}^{1}$ are aligned in a transverse lamina in A. namaquensis, while in A. chrysophilus the more posterior t1 gives a convex outline to the first lobe. 
In both Aethomys species examined here there is no strong development of stephanodont crests. The link between $\mathrm{t} 6$ and $\mathrm{t} 9$ may occur at very worn molars, earlier in A. namaquensis than in A. chrysophilus. On the $\mathrm{M}_{1}$, the longitudinal crest linking the prelobe to the first lobe, appears earlier in A. namaquensis (stage 2-3) than in A. chrysophilus (no link appearing or never before stage 5) (Fig. 1).

A. namaquensis is clearly different from A. chrysophilus in the lower molars. It has an accessory anterior cusp or tma, which gives a different disposition of the anterior main cusps of the prelobe and it has also a big labial cingulum upon which numerous cingular supplementary cusplets develop. A. chrysophilus has a less developed, more discontinuous cingulum, and shows only cusplet cv5 (Fig. 1). The development of the posterior cingulum on the $\mathrm{M}_{1-2}$ is subject to high variability. The acquisition of numerous supplementary cusplets is considered as a derived character (Denys et al. 1992). By contrast, the fossil specimens from the Plio-Pleistocene sites of South Africa attributed to A. cf. namaquensis do not show so many supplementary cusplets.

\section{Comparison with non-Mozambian A. namaquensis and A. chrysophilus}

A comparison with other modern representatives of both species has been undertaken in order to verify whether the Mozambique populations of Aethomys show only local modifications of their molar structure or are similar to other ones. Comparison with other South African populations shows no important differences in the dental patterns. However, some A. chrysophilus representatives show more longitudinal crests in a population from Zimbabwe (MNHN collections). The systematics of the latter species has not been revised since more than 40 years, and the observed differences in the Zimbabwe population may point to the fact that they belong to another species. The development of the supplementary cingular cusplets on the lower molars of other A. namaquensis representatives is identical to the ones of the Mozambique population.

\section{Discussion}

Differences in molar morphology are observed between the two Aethomys species living in the same community in Mozambique. These differences are similar to those observed between the same species in South Africa. The question now is which of these differences is related to diet?

A. namaquensis shows many supplementary cingular cusplets, bunodont cusps, and longitudinal crests appearing relatively early, all these characteristics are considered as derived (Misonne 1969, Michaux 1971). On the contrary, A.chrysophilus has retained a more primitive dental pattern. According to Gliwicz (1985, 1987) in Mozambique, A. namaquensis is primarily a folivore and grasseater. The latter feature could explain the existence of small "stephanodont" crests, occuring earlier, in A. namaquensis contrary to A. chrysophilus. During the dry season, $A$. namaquensis does not eat any insects in contrast to $A$. chrysophilus, which has a 
wider spectrum of food. The development of longitudinal crests and of supplementary labial cingular cusps can be put in relation with a mainly vegetarian diet. As a matter of fact, the development of stephanodont crests reaches a maximum in another purely vegetarian murid of Africa: Thallomys, the diet of which being strictly vegetarian (Kingdon 1974). Similarly, Thallomys has a well developped labial cingular margin, but less supplementary cusplets on it.

A. chrysophilus has a standard murine dental pattern, which is rather close to the one of Rattus rattus, well known to be omnivorous. In Mozambique, Gliwicz (1987) found a less specialized $\operatorname{diet}$ for A. chrysophilus compared to A. namaquensis, especially during the dry season.

In summary, the present study shows that bunodonty associated with stephanodonty indicate a vegetarian diet.

\section{Application to fossil Aethomys from Langebaanweg}

The Langebaanweg site (Pliocene, 5 Myrs, Cape Region, South Africa) has yielded in the same levels well-preserved dental remains of two extinct Aethomys species (Denys 1990a, b) (Fig. 2). The two species show different molar morphology and probably belong to different lineages. The first species, A. adamanticola, is the larger of the two and is characterized by large and low cusps, relatively columnars. There is no tma on the lower molar, the cingular margin is discontinuous with two cusps. Longitudinal crests are absent on the lower molars at early stages of wear and there is no link t6-t9. This structure of the cusps is rather primitive and corresponds to a relatively generalized dental pattern. In regard to the previous results on modern Aethomys, it is highly probable that A. adamanticola would have been omnivorous like in the modern A. chrysophilus. The second fossil species of Langebaanweg is A. modernis. This smaller species shows more derived dental characters like the tma, the existence of a link prelobe - first lobe on $\mathrm{M}_{1}$ and an early development of the crest between $t 6$ and t9. A. modernis does not show such a developped labial cingular margin as the modern $A$. namaquensis. In A. modernis, the tma of the prelobe is rather small and the posterior cingulum on
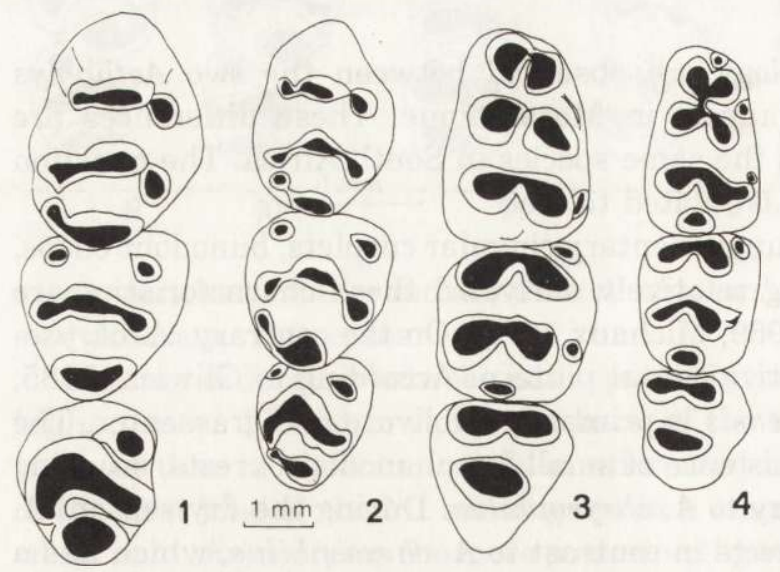

Fig. 2. Dental patterns of the two fossil species of Langebaanweg, reconstituted dental raws: (1) A. adamanticola (SAM PQL $14828 \mathrm{M}^{1-2}, 42570 \mathrm{M}^{3}$ ), (2) $A$. modernis (SAMPQL $14828 \mathrm{M}^{1}$, L33814 $\mathrm{M}^{2-3}$ ); (3): A. adamanticola (SAM PQL 50606), (4): A. modernis (SAM PQL 42987). All specimens come from the Pellet Phosphorit Member. 
$\mathbf{M}_{1-2}$ is important, while in $A$. namaquensis the latter is absent on $\mathbf{M}_{1}$. This could be an indication that the fossil $A$. modernis from Langebaanweg had a rather more generalized diet than is the case for the modern $A$. namaquensis, but was more vegetarian than $A$. adamanticola. It is possible to make derive modern $A$. namaquensis from both Langebaaweg species. The development of bunodonty, and of an enlarged cingular labial margin with many supplementary cusplets, among the A. namaquensis lineage could be the result of a shift toward a mainly vegetarian diet. The succession between the Plio-Pleistocene fossils of the Transvaal in South Africa and the modern forms is not continuous, and, in this region there is now an important gap in the fossil-record for the last 1.5-1 Ma. The first modern representatives of $A$. namaquensis and A. chrysophilus appears around $3.7 \mathrm{Ma}$ (at Makapansgat, South Africa; Pocock 1987). None of the Plio-Pleistocene fossils of the well-documented faunas of South Africa show a similar development of the supplementary cusps of the cingular margin of the $\mathrm{M}_{1}$ as the modern A. namaquensis. The trend toward the development of bunodonty in A. namaquensis could result from a late change in the diet, which occurred after 1.5-1 Ma.

\section{Conclusion}

It is shown here that the ecologically most specialized $A$. namaquensis shows the most specialized dentition. The strong bunodonty of the dentition of $A$. namaquensis is related with mainly vegetarian diet. The presence of slightly developed stephanodont crests in A. namaquensis is also an indication of the vegetarian diet. A. chrysophilus, from Mozambique, do not show any longitudinal crests. The generalized dental pattern of $A$. chrysophilus can be related to an omnivorous diet similar to that found in Rattus rattus.

The two fossil Aethomys form Langebaanweg show different dental morphologies indicating different diets. One of the lineage leading to A. namaquensis shows a morphological shift that can be interpreted here has the acquisition of a mainly vegetarian diet.

For rodents, dental morphology can be a tool for a better understanding of paleodiets, as well as for the understanding of evolutionary differences in dental morphology between species. This method must be supplemented by other techniques, such as $\mathrm{Sr}$ content, or isotopes ratios, or microwear examination, despite some limitations noted elsewhere (Dauphin and Denys 1992). The African rodents diets have been very poorly investigated and further studies may provide important data for a better understanding of their extinct relatives and their evolution.

Acknowledgements: This work has been funded by an International Cooperation grant from French CNRS and Polish Academy of Sciences. I wish to thank K. Kowalski for giving opportunity to study this material and for his careful review of the manuscript. Thanks also are due to the curators of the following Museums for providing comparison materiel for this study: G. Bronner (Transvaal Museum), P. Jenkins (NHM London), S. George (LACM, Los Angeles), J. Cuisin, M. Tranier (MNHN Paris), Q. B. Hendey and M. D. Avery (South African Museum, South Africa). The comments of J. Michaux on the manuscript were very useful. The English has been corrected by Dr M. Ruse from Toronto. 


\section{References}

Davis D. H. S. 1975. Genus Aethomys. Part 6.6. [In: The mammals of Africa. An identification manual. J. Meester and H. W. Setzer, eds]. Smiths. Inst. Press, Washington: 1-9.

Dauphin Y. and Denys C. 1992. Diagénèse différentielle chez les rongeurs fossiles - validité des paramètres géochimiques pour les reconstitutions des régimes alimentaires. Pal. Pal. Pal. 99: 213-223.

Denys C. 1990a. Deux nouvelles espèces d'Aethomys (Rodentia, Muridae) à Langebaanweg (Pliocène, Afrique du Sud): Implications phylogénétiques et paléoécologiques. Ann. Paleont. 76: 41-69.

Denys C. 1990b. Implications paléoécologiques et paléobiogéographiques de l'étude de rongeurs plio-pléistocènes d'Afrique orientale et australe. $\mathrm{Ph}$. D. thesis, Mém. Sci. Terre. Université Paris VI: $1-595$.

Denys C., Michaux J., Petter F., Aguilar J. P. and Jaeger J. J. 1992. Molar morphology as a clue to the phylogenetic relationship of Acomys to the Murinae. Isr. J. Zool. 38: 253-262.

Gliwicz J. 1985. Rodent community of dry African savanna: population study. Mammalia 49: 509-516.

Gliwicz J. 1987. Niche segregation in a rodent community of african dry savanna. J. Mammal. 68: 169-172.

Jacobsen N. H. G. 1977. An annotated checklist of the amphibians, reptiles and mammals of the Nylsvley Nature Reserve. S. Afr. Nat. Sci. prog. Rpt. 21: 1-65.

Jaeger J. J. 1983. Equilibres ponctués et gradualisme phylétique: un faux débat? [In: Modalités, rythmes et mécanismes de l'évolution biologique]. Coll. Intern. C.N.R.S. Ed. Paris: 145-153.

Kay R. F. and Hylander W. L. 1978. The dental structure of mammalian folivores with special references to Primates and Phangeroidea (Marsupialia). [In: The ecology of arboreal folivores. G. G. Montgomery, ed]. Smithsonian Institution Press, Washington: 173-191.

Kingdon J. 1974. East African mammals. Vol. II B . (Hares and rodents). The University of Chicago Press, Chicago: 1-704.

Meulen A., van der and Bruijn H., de 1982. The mammals from the lower Miocene of Aliveri (island of Evia, Greece). Part II: The Gliridae. Proc. Kon. Ned. Akad. Wetensch. B, 85: 485-524.

Michaux J. 1971. Muridae (Rodentia) Neogènes d'Europe sud-occidentale. Evolution et rapports avec les formes actuelles. Paleobiologie continentale 2: 1-67.

Misonne X. 1969. African and Indo-Australian Muridae evolutionary trends. Ann. Mus. Roy. Afr. Centr. Tervuren, Sci. Zool. 172: 1-219.

Pocock T. 1987. Plio-Pleistocene mammalian microfauna of southern Africa. A preliminary report including description of two new fossil muroid genera (Mammalia, Rodentia). Pal. Africana. 26: 69-91.

Roberts A. 1951. The mammals of South Africa. Trustees of the Mammals of South Africa Book Fund. Johannesbourg: 1-700.

Shortridge G. C. 1934. The mammals of South-West Africa. Vol. I. W. Heinemann, London: 1-437.

Smithers R. H. N. 1971. The mammals of Botswana. Mus. Memoir Trustees of the Nat. Mus. Rhodesia, Salisbury: 1-340.

Smithers R. H. N. 1983. The mammals of the southern Africa sub-region. University of Pretoria. Pretoria: $1-736$.

Stehlin H. G. and Schaub S. 1951. Die trigonodontie der simplicidenten Nager. Birkhäuser Verlag, Basel: 1-385.

Vesey-Fitzgerald D. F. 1966. The habits and habitats of small mamals in the Congo river catchment region of Zambia and Tanzania. Zool. afr. 2 (1): 111-122.

Received 31 May 1994, accepted 12 September 1994. 